\title{
A Strong Wind Could Blow It Over: Understanding the Fragile State of Music Blockchain Development in Contrast to the Antifragile State of Blockchain Tech Generally
}

\author{
George Howard \\ Berklee College of Music \\ This paper was presented at the 2019 International Summit of the \\ Music \& Entertainment Industry Educators Association
}

March 21-23, 2019

\section{https://doi.org/10.25101/19.23}

\section{Abstract}

Blockchain technology has moved from something associated entirely with Bitcoin and only whispered about in the recesses of the internet to a now nearly all-pervasive presence across a wide range of industries. In the years since the emergence of Blockchain technology it has withstood not only the countless naysayers who pooh-poohed its very existence as nothing more than vapor-y trend, but also countless attacks and code exploitations across various Blockchain implementations (specifically, the Bitcoin and Ethereum Blockchains). This durability in the face of tremendous adversity has led to my thesis that Blockchain Technology has moved from a state of Fragility to a now Antifragile state, in which it is not only able to survive threats and attacks (defined as "robustness"), but actually gains strength from these attacks.

This concept of Fragility/Antifragility was codified by Nassim Taleb in his book Antifragile, and builds upon the concept of the Lindy Effect. It is widely applicable to Blockchain Technology as, as stated above, this technology appears to exhibit the requisite characteristics to be defined as Antifragile. However, Blockchain Technology as it relates directly to the music industry is exhibiting the polar opposite attributes; it is deeply Fragile. Blockchain as it relates to the music business has become something of an imperative for any music business participant who is forward-thinking. The promise of a decentralized, immutable ledger with machine-readable rights is far too compelling to be ignored by those who believe the music industry is in need of wholesale change. And yet, even with no shortage of investment dollars and (relatively) high profile attempts to leverage the above-referenced characteristics of Blockchain into viable solutions/businesses in the music industry ecosystem, one would be hard-pressed to point to a single example of success.

As someone who has both worked in the Blockchain space since the very beginning, and chronicled its development in music and other industries in my Forbes column, I have unique line of sight as to why Blockchain and music remains in this extremely Fragile state, even while Blockchain Technology across other industries is only becoming more robust. This paper will provide:

- An overview of the current state of Blockchain Technology, generally, and Blockchain Music implementation, specifically

- Identify and explain the four dominant reasons why Blockchain Technology has not gained traction in the industry

- Delineate the necessary steps that must be taken to address the above referenced points of failure

- Provide a specific example of what such an implementation would resemble

- Address the specific problems this type of Blockchain-based Music implementation would address with respect to the music industry, generally

- How best to integrate the challenges and opportunities of Blockchain based music implementation in the classroom.

Keywords: blockchain, music industry, Nassim Taleb, fragility, antifragility

George Howard is an Associate Professor of Management at Berklee College of Music where he teaches courses in entrepreneurship, marketing, copyright law, and leadership. He is the recipient of the Distinguished Faculty Award, the Dean's Award for Teaching Excellence, and the Dean's Award for Global Presence and Engagement. Via his con- 
sulting firm, Mr. Howard advises a wide-range of clients on how to integrate technology with strategy in order to increase awareness and revenue. A partial list of clients includes: Intel, National Public Radio, CVS/pharmacy, Easter Seals, Brown University, IBM, PWC, Alticor/Amway, Composer Mark Isham, Snowbird Ski and Summer Resort, Paste Magazine, The Estate of the Platters, and Daytrotter. Mr. Howard is a columnist for Forbes and a frequent contributor to the New York Times and numerous other publications. His most recent book is Everything In Its Right Place: How Blockchain Technology Will Lead To A More Transparent Music Industry. Howard holds an MA, MBA, and JD.

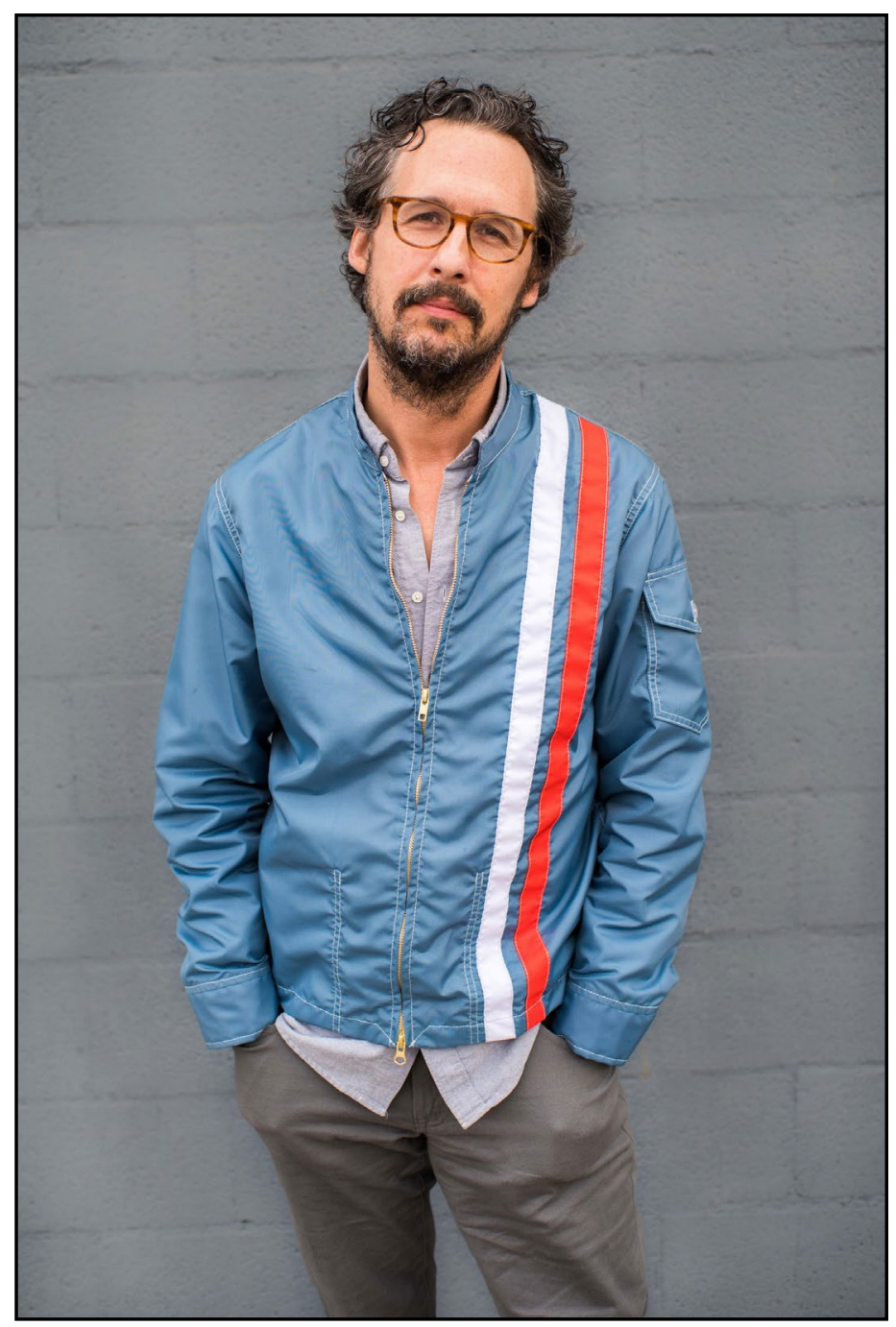




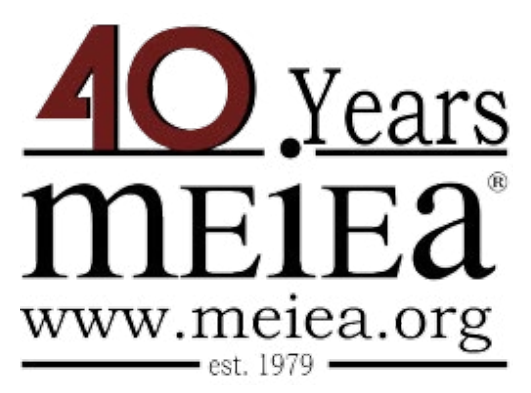

\section{PROCEEDINGS OF THE \\ 2019 INTERNATIONAL SUMMIT \\ OF THE \\ MUSIC \& ENTERTAINMENT \\ INDUSTRY EDUCATORS \\ ASSOCIATION}

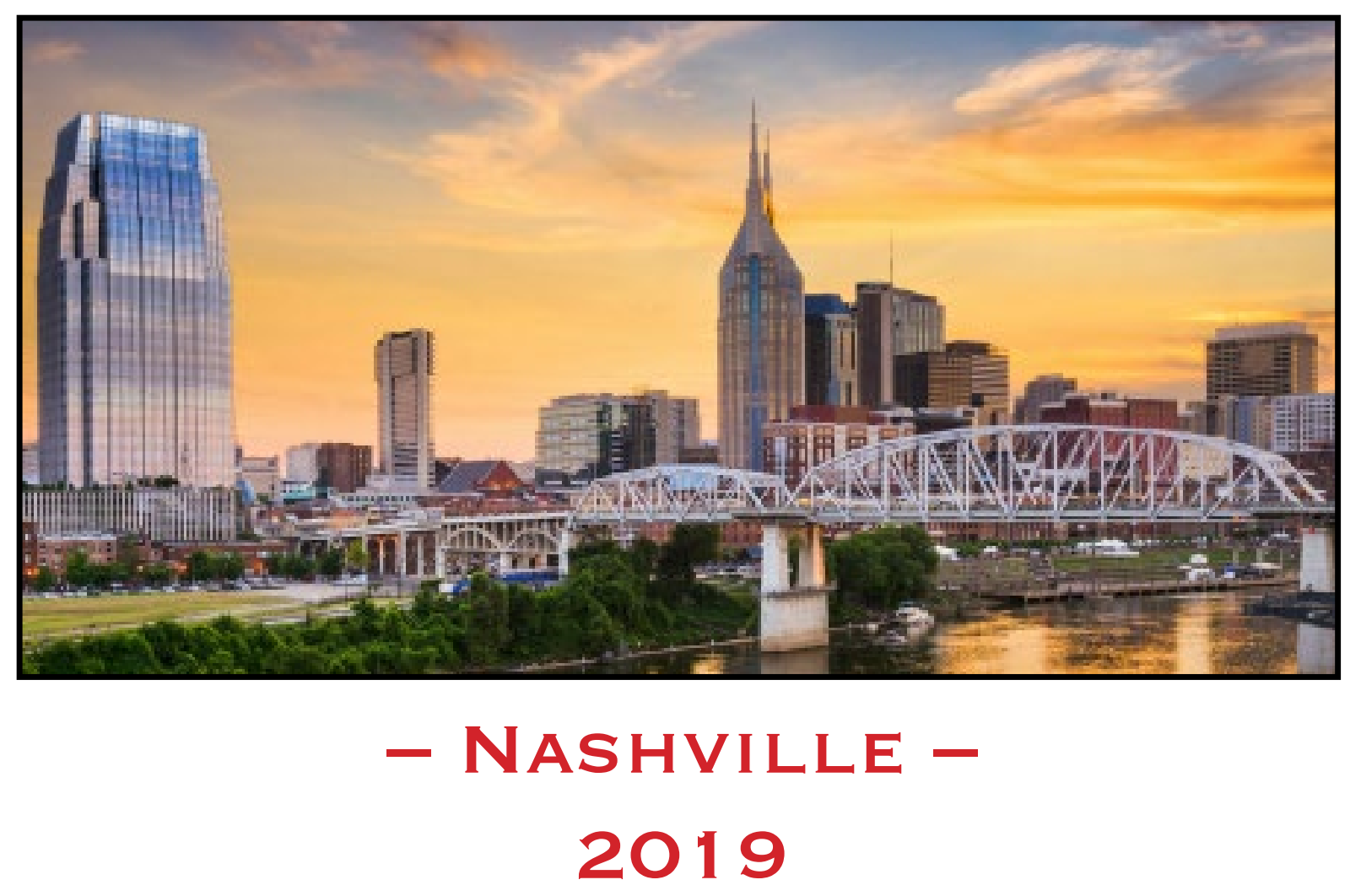

March 21 - 23, $2019 \cdot$ Belmont University - Nashville 